Article

\title{
Spatial-Temporal Differentiation and the Driving Mechanism of Rural Transformation Development in the Yangtze River Economic Belt
}

\author{
Rongtian Zhang ${ }^{1, *}$ and Xiaolin Zhang $^{2}$ \\ 1 Research Institute of Rural Revitalization Strategy, Yangzhou University, Yangzhou 225009, China \\ 2 School of Geographic Sciences, Nanjing Normal University, Nanjing 210046, China; zhangxiaolin@njnu.edu.cn \\ * Correspondence: rtzhang@yzu.edu.cn
}

Citation: Zhang, R.; Zhang, X. Spatial-Temporal Differentiation and the Driving Mechanism of Rural Transformation Development in the Yangtze River Economic Belt. Sustainability 2022, 14, 2584. https:// doi.org/10.3390/su14052584

Academic Editor: Gema Cárdenas Alonso

Received: 17 January 2022

Accepted: 17 February 2022

Published: 23 February 2022

Publisher's Note: MDPI stays neutral with regard to jurisdictional claims in published maps and institutional affiliations.

Copyright: (C) 2022 by the authors. Licensee MDPI, Basel, Switzerland. This article is an open access article distributed under the terms and conditions of the Creative Commons Attribution (CC BY) license (https:// creativecommons.org/licenses/by/ $4.0 /)$.

\begin{abstract}
Rural transformation development is an important part of rural revitalization, and the study of spatial-temporal differentiation characteristics and the driving mechanism of rural transformation development can provide a decision-making reference for formulating rural revitalization programs according to local conditions. Taking the Yangtze River Economic Belt as the research case, we constructed an evaluation system of rural transformation development in the dimension of "population, land and industry", and the entropy TOPSIS method, spatial autocorrelation model and geographic detector model were used to reveal spatial-temporal differentiation and the driving mechanism of rural transformation development in the Yangtze River Economic Belt from 1978 to 2018. The results showed that (1) rural transformation development has been significantly unbalanced in the Yangtze River Economic Belt, and rural transformation development showed a weak distribution. Moreover, in terms of dimensions, the land use transformation level > population development transformation level > industrial development transformation level. (2) On the global, rural transformation development presented a spatial distribution trend of club convergence. On the local, the $\mathrm{H}(\mathrm{High})-\mathrm{H}(\mathrm{High})$ type was mainly distributed in Shanghai City and the southern part of Jiangsu Province, and it evolved to Hangzhou-Shaoxing-Ningbo and Wanjiang City Belt; the L(Low)L(Low) type was mainly concentrated in the western part of Sichuan Province and in the southwest of Yunnan Province. (3) Natural conditions, economic social development, traffic accessibility, policies and systems were the leading factors affecting rural transformation development in the Yangtze River Economic Belt. The influences of economic social development and traffic accessibility on rural transformation development were increasing, and policy factors had an important guiding effect on rural transformation development, and the influence of natural conditions on rural transformation development has weakened. This study can provide a practical reference for rural transformation and rural revitalization in the Yangtze River Economic Belt.
\end{abstract}

Keywords: rural transformation development; spatial-temporal pattern; influencing factors; mechanism; the Yangtze River Economic Belt

\section{Introduction}

Rural is a regional spatial system, which refers to the regional complex outside the urban built-up area, with natural, social and economic characteristics and multiple functions of production, life, ecology and culture [1]. Since the reform and opening up with the development of China's market economy, urbanization and industrialization continue to accelerate; as a result, the factors of production, such as rural manpower, land and capital, have been transferred to non-agricultural industries, and the factor structure and regional functions of the rural regional system have undergone a significant transformation [2]. Faced with many problems and contradictions in the process of rural development in China, the strategy of rural revitalization has been put forward, and the strategy of rural revitalization has become an important policy orientation for rural development in China. 
The strategic goal of rural revitalization is to reorganize the elements of a rural regional system, reshape the structure of a rural regional system and then realize the optimization of rural regional functions [3]. Therefore, the discussion of the evolution process of China's rural regional system from the perspective of rural regional elements, functional transformation and spatial reconstruction can provide theoretical support for the implementation of China's rural revitalization strategy.

Rural transformation development is the main characteristic of contemporary rural development; it has become the focus of geography, sociology and economics [4-7]. If the transformation is mainly understood as the qualitative change from one kind of social organization to another kind of social organization, then what does rural transformation mean? The popular transition is from "productive countryside" to "post-productive countryside". Hoggart [8] believed that rural transformation, as an analysis method, should emphasize the overall analysis of the change process and be a comprehensive description of the characteristics of rural change. Liu [9] believed that rural transformation development is the process of realizing the transformation of traditional rural industry, the production mode and the consumption structure, as well as the continuous transformation from an urban-rural dual structure to urban-rural integrated development; the goal is to realize the all-round transformation of regional urban-rural relations and the relations between industry and agriculture. Long [10] believed that rural transformation development is a process of rural spatial pattern and economic social form reconstruction in the process of rapid industrialization and urbanization, due to the recombination and interaction of urban and rural population flow and economic social development factors, and local participants respond to these changes. The paper argues that the connotation of rural transformation development mainly refers to that within the background of rapid industrialization and urbanization, urban and rural population flow and the influence factors, such as industrial structure adjustment and interaction, which lead to the reconstruction of the rural economic and social form and regional space pattern; it includes the rural industrial structure transformation, rural employment structure transformation, the structure of the rural residential areas and rural social and cultural structure transformation.

The study of rural transformation development has experienced a process of cultural transformation, from the study of modernist rural society to the study of new rural sociology and then to the study of rural studies [11]. There are obvious differences between developed countries and China in terms of rural transformation and development, but it can be seen that studies on rural transformation focus on the sociological category [12]. According to the summary, the current research content mainly focuses on regional differences [13,14], influencing factors and driving mechanisms [15,16], regional patterns [17,18] and the relationship with land use transformation development $[19,20]$; in addition, an empirical study was conducted on the transformation development characteristics of typical characteristic villages $[21,22]$. In terms of research methods, it mainly used qualitative research and quantitative methods to carry out the analysis; qualitative research mainly adopted field questionnaire surveys [5] and structured interviews [23], and quantitative research mainly adopted " $3 S^{\prime}$ " technology [24,25], econometric models [26,27] and other methods. The research on rural transformation development has been deepened from the macroscopic and mesoscale scale [28,29] to the microscopic scale [30-32]; it shows a trend of multi-scale research. In general, since the 1990s, developed countries have been reflecting on the development mode of large-scale urbanization and trying to redefine the significance of rural existence and the future of rural areas, which has a certain inspiration for post-modern countries. Rural transformation is an important issue in the field of rural development; although we have a preliminary understanding of the connotation of rural transformation, the systematic elaboration of the concept connotation of rural transformation is still relatively underdeveloped. In terms of specific research ideas and paradigms, studies on rural transformation development from the perspective of "model-mechanism-regulation" are relatively weak, and the laws of rural transformation development in typical regions have not been revealed and summarized enough. 
Therefore, the paper chose the Yangtze River Economic Belt as a typical case study, based on rural transformation theory, and it comprehensively applied a variety of methods to study the spatial-temporal pattern differentiation and the driving mechanism of rural transformation development. A brief structure of the manuscript mainly included three parts, namely:

- How to measure the characteristics of the rural transformation development level. In this part, it mainly constructed the evaluation index system of rural transformation development, and it used the entropy weight TOPSIS method to evaluate the rural transformation development level of the Yangtze River Economic Belt.

- How to reveal the spatial-temporal differentiation pattern of rural transformation development. In this part, using the spatial autocorrelation analysis model, the paper revealed the evolution of the spatial pattern of rural transformation development from the perspectives of global autocorrelation and local autocorrelation.

- How to explore the driving mechanism of rural transformation development differentiation. In this part, the influencing factors of rural transformation development in the Yangtze River Economic Belt were revealed by using the Geographic Detector Model, and the driving mechanism of rural transformation development was summarized.

\section{Materials and Methods}

\subsection{Study Area}

The Yangtze River Economic Belt covers 11 provinces, including Shanghai, Jiangsu, Zhejiang, Anhui, Jiangxi, Hubei, Hunan, Chongqing, Sichuan, Yunnan and Guizhou, and it straddles the eastern, middle and western regions of China (Figure 1). It covers an area of about 2.05 million square kilometers, and it has $21 \%$ of the drainage area of the country, abundant natural resources and a unique ecosystem. By the end of 2018, the population of the Yangtze River Economic Belt had reached 598.73 million, accounting for 42.91 percent of the national total; the GDP of the Yangtze River Economic Belt reached 40,288.524 billion yuan, accounting for 44.75 percent of the national total. Since its reform and opening up, the Yangtze River Economic Belt has developed into a region with the strongest comprehensive strength and the greatest strategic support, and it has become one of the national strategies.

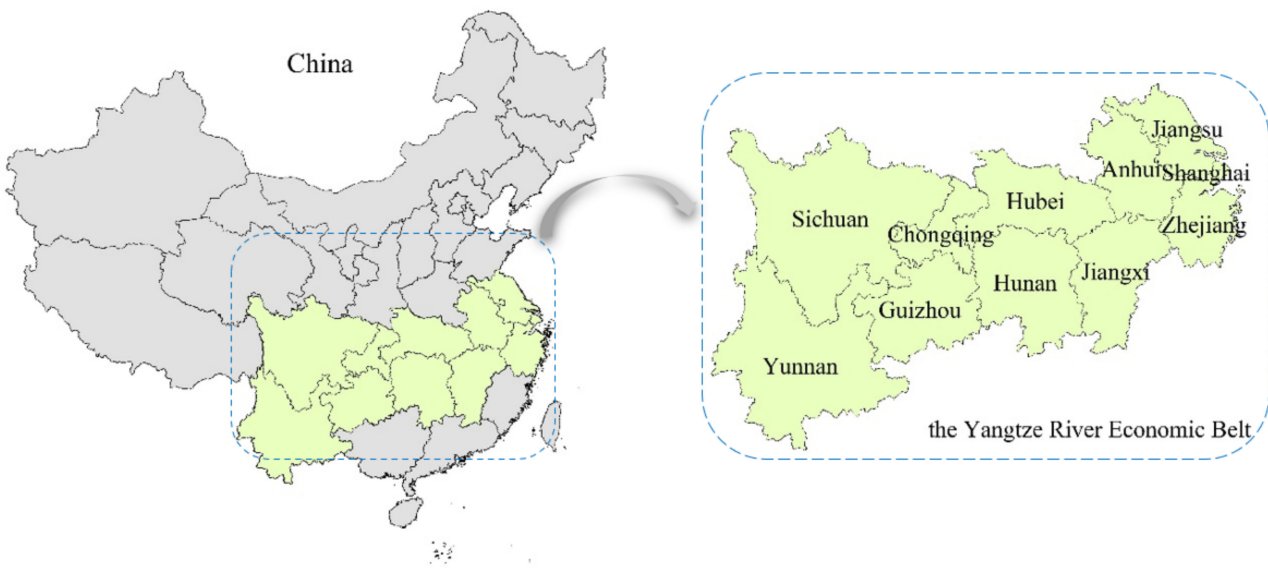

Figure 1. The geographical location of the Yangtze River Economic Belt.

\subsection{Index System and Data Collection}

\subsubsection{Index System}

Based on the connotation characteristics of rural transformation development, this paper refers to the research results of the rural transformation development evaluation index system. In this paper, the evaluation index system of the rural transformation development level of The Yangtze River Economic Belt was constructed from the dimension of "population-land-industry" [33,34] (Table 1). (1) Population development transformation. This mainly reflects the spatial shift of the urban and rural population and the change 
of employment structure. Indicators such as urbanization rate $\left(\mathrm{X}_{1}\right)$, proportion of rural non-agricultural employment $\left(X_{2}\right)$ and proportion of non-agricultural income $\left(X_{3}\right)$ were selected. (2) Land use transformation. This mainly reflects the changes in the scale and structure of the rural production and living and ecological land. Indicators such as the proportion of cultivated land areas $\left(X_{4}\right)$, proportion of woodland areas $\left(X_{5}\right)$ and proportion of rural residential land $\left(X_{6}\right)$ were selected. (3) Industrial development transformation. This mainly reflects the development characteristics of the industrial structure and agricultural modernization level in rural areas. Indicators such as the proportion of the output value of secondary and tertiary industries $\left(X_{7}\right)$, the proportion of machine-cultivated areas $\left(X_{8}\right)$ and agricultural labor productivity $\left(X_{9}\right)$ were selected.

Table 1. Evaluation index system of rural transformation development.

\begin{tabular}{|c|c|c|}
\hline System Layer & Elements Layer & Index Layer \\
\hline \multirow{3}{*}{$\begin{array}{c}\text { Rural transformation } \\
\text { development }\end{array}$} & $\begin{array}{l}\text { Population development } \\
\text { transformation }\end{array}$ & $\begin{array}{c}\text { Urbanization rate }\left(X_{1}\right) \\
\text { Proportion of rural non-agricultural } \\
\text { employment }\left(X_{2}\right) \\
\text { Proportion of non-agricultural } \\
\text { income }\left(X_{3}\right)\end{array}$ \\
\hline & Land use transformation & $\begin{array}{c}\text { Proportion of cultivated land } \\
\text { areas }\left(X_{4}\right) \\
\text { Proportion of woodland areas }\left(X_{5}\right) \\
\text { Proportion of rural residential } \\
\text { land }\left(X_{6}\right)\end{array}$ \\
\hline & $\begin{array}{l}\text { Industrial development } \\
\text { transformation }\end{array}$ & $\begin{array}{c}\text { Proportion of the output value of } \\
\text { secondary and tertiary industries }\left(X_{7}\right) \\
\text { Proportion of machine-cultivated } \\
\text { areas }\left(X_{8}\right) \\
\text { Agricultural labor productivity }\left(X_{9}\right)\end{array}$ \\
\hline
\end{tabular}

\subsubsection{Data Collection}

The research data mainly included the Shanghai Statistical Yearbook, Jiangsu Statistical Yearbook, Zhejiang Statistical Yearbook, Anhui Statistical Yearbook, Jiangxi Statistical Yearbook, Hunan Statistical Yearbook, Hubei Statistical Yearbook, Chongqing Statistical Yearbook, Sichuan Statistical Yearbook, Guizhou Statistical Yearbook, Yunnan Statistical Yearbook and statistical bulletins of the national economic and social development of each province. The data of all roads are from the traffic almanac of 11 provinces in the Yangtze River Economic Belt were included. The operating mileage of high-speed railway lines in 11 provinces in the Yangtze River Economic Belt was obtained through the website of the National Railway Administration, Baidu information and map. The operating mileage of high-speed railway lines was further added up year by year to obtain the total mileage data of high-speed railways in all provinces.

The spatial analysis scale was 127 cities of the Yangtze River Economic Belt, and the city boundary map was mainly taken from the Shanghai Atlas, Jiangsu Atlas, Zhejiang Atlas, Anhui Atlas, Jiangxi Atlas, Hunan Atlas, Hubei Atlas, Chongqing Atlas, Sichuan Atlas, Guizhou Atlas and Yunnan Atlas.

\subsection{Research Methods}

\subsubsection{Entropy TOPSIS Method}

Entropy TOPSIS is a sorting method that approximates the ideal value; it was first proposed by Hwang et al. in 1981. Entropy TOPSIS is based on the traditional TOPSIS method, effectively overcoming the subjective factors of evaluation. It can objectively reflect the dynamic changes of evaluation indexes and is suitable for the comprehensive evaluation of multiple indexes [35,36]. In view of this, this paper adopted the entropy TOPSIS method to evaluate the rural transformation development of the Yangtze River Economic Belt. The steps were as follows:

(1) Construct an evaluation index system matrix, $X . X=\left(\mathrm{x}_{\mathrm{ij}}\right)_{\mathrm{m} \times \mathrm{n}}$; 
(2) Standardization of the index matrix. $x_{\mathrm{ij}}^{\prime}=\mathrm{x}_{\mathrm{ij}} / \mathrm{x}_{\max }$;

(3) Calculate the evaluation index entropy value, $H_{i} . H_{i}=-\frac{1}{\operatorname{lnm}}\left(\sum_{\mathrm{j}=1}^{\mathrm{m}} \mathrm{f}_{\mathrm{ij}} \operatorname{lnf} \mathrm{fij}_{\mathrm{ij}}\right)$;

(4) Determine the entropy weight of the evaluation index. $\mathrm{W}=\left(\mathrm{w}_{\mathrm{i}}\right)_{1 \times \mathrm{n}}$;

(5) Determine the optimal solution, $S_{j}^{+}=\max \left(r_{1 j}, r_{2 j}, \ldots, r_{n j}\right), S_{-j}^{-}=\min \left(r_{1 j}, r_{2 j}, \ldots, r_{n j}\right)$;

(6) Calculate the euclidean distance between the optimal solution and the worst solution.

$$
\mathrm{D}_{\mathrm{i}}^{+}=\sqrt{\sum_{\mathrm{j}=1}^{\mathrm{n}}\left(\mathrm{s}_{\mathrm{j}}^{+}-\mathrm{r}_{\mathrm{ij}}\right)^{2}}, \mathrm{D}_{\mathrm{i}}^{-}=\sqrt{\sum_{\mathrm{j}=1}^{\mathrm{n}}\left(\mathrm{s}_{\mathrm{j}}^{-}-\mathrm{r}_{\mathrm{ij}}\right)^{2}} ;
$$

(7) Measure the level of rural transformation development. $C_{i}=\frac{D_{i}^{-}}{D_{i}^{+}+D_{i}^{-}}$.

\subsubsection{Spatial Autocorrelation Model}

The spatial-temporal pattern of rural transformation development in the Yangtze River Economic Belt was measured by the global Moran's I and local LISA index. The global Moran's I index analyses the overall pattern of regional rural transformation development, and it reveals the spatial correlation characteristics of rural transformation development. The local LISA index describes the local spatial heterogeneity in rural transformation development, and it identifies the correlation characteristics of local different spatial positions [37-39].

(1) Global Moran's I

$$
I(d)=\frac{\sum_{i=1}^{n} \sum_{j=1}^{n}\left(X_{i}-\bar{X}\right)\left(X_{j}-\bar{X}\right)}{S^{2} \sum_{i=1}^{n} \sum_{j=1}^{n} W_{i j}} ; S^{2}=\sum_{i=1}^{n}\left(X_{i}-\bar{X}\right)^{2} / n
$$

where $X_{i}$ is the observed value of region $i ; X_{j}$ is the observed value of region $j ; W_{i j}$ is the spatial weight matrix. When $I(d)>0$, there is a positive spatial correlation, indicating that regions with a high (low) level of rural transformation development gather significantly in space and vice versa.

(2) Local LISA index

$$
I_{i}=Z_{i}^{\prime} \sum_{j=1}^{n} W_{i j} Z_{j}^{\prime}
$$

where $\mathrm{Z}_{\mathrm{i}}^{\prime}$ and $\mathrm{Z}_{\mathrm{j}}^{\prime}$ are the standardization of rural transformation development on the $i$ and $j$; when $I_{i}>0$, it indicates that there is little difference between the rural transformation development level and surrounding areas; when $I_{i}<0$, it indicates that there is a big difference between the rural transformation development level and the surrounding area.

\subsubsection{Geographic Detector Model}

The geographic detector model is a new statistical method, and based on GIS spatial superposition technology and set theory, multi-factor interaction models are identified [40]. It determines whether the independent variable has an influence on the dependent variable and the degree of influence by detecting whether the spatial distribution of the dependent variable and independent variable is consistent; the spatial analysis of each influencing factor can be explored, and the driving factors behind the differentiation can be revealed. In view of this, the geographical detector model was used to analyze the influence mechanism of physical geography, economic society, policy and other factors on regional rural transformation development differentiation $[41,42]$. The theoretical model is as follows:

$$
P_{D, H}=1-\frac{1}{N^{\prime} \sigma_{H}^{2}} \sum_{\mathrm{w}=1}^{m} n_{D, W} \sigma_{H_{D, W}}^{2}
$$


where $P_{H, D}$ is the influence that factor $D$ has on the rural transformation development level $H ; \sigma_{H}^{2}$ is the horizontal variance of rural transformation development; $\sigma_{H_{D, W}}^{2}$ is the horizontal variance of rural transformation development in the sub-region $\mathrm{W} ; \mathrm{N}^{\prime}$ is the sample number of the whole region; the $P_{D, H}$ value range is [0,1]; if $P_{H, D}$ is larger, it indicates that this factor has a greater influence on rural transformation development.

\section{Results}

\subsection{Temporal Variation Characteristics}

According to the evaluation index system of rural transformation development, the original analysis data of 127 city units of the Yangtze River Economic Belt were collected, and the entropy TOPSIS model was used to calculate the level of rural transformation development in the Yangtze River Economic Belt from 1978 to 2018. Frequency distribution was used to characterize the distribution characteristics of the rural transformation development level at the urban scale in the Yangtze River Economic Belt from 1978 to 2018 [43] (Figures 2 and 3).

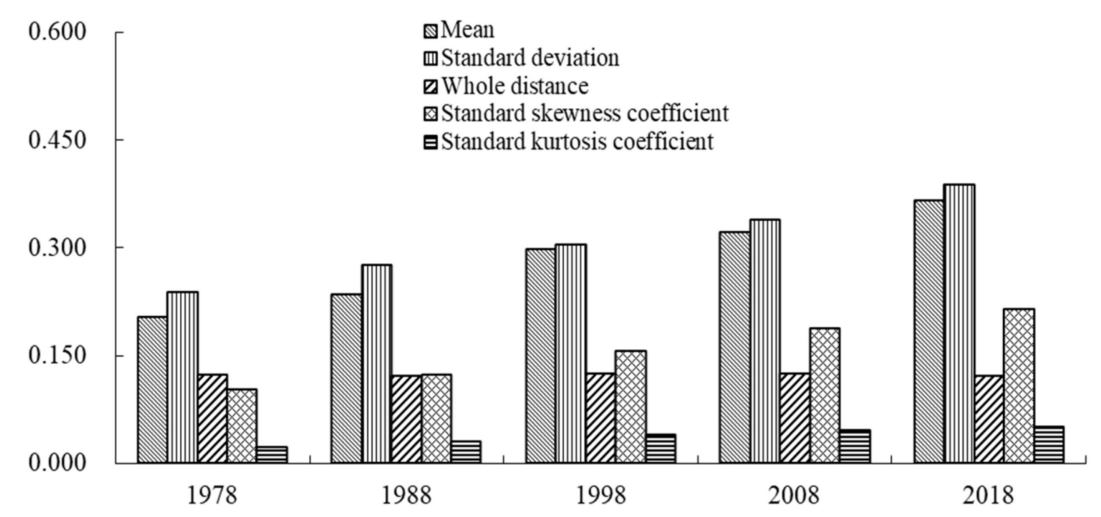

Figure 2. The characteristics of the frequency distribution of rural transformation development.

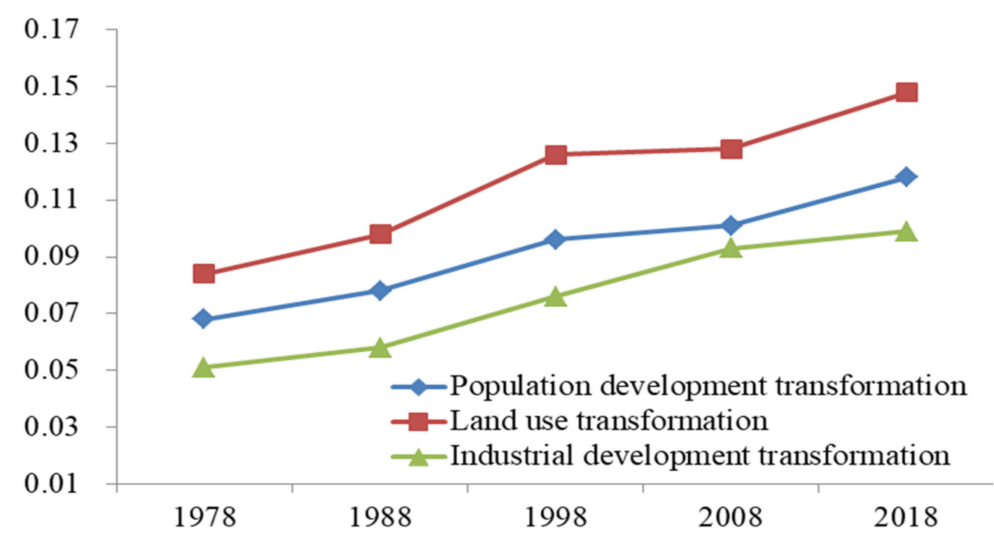

Figure 3. Evaluation of rural transformation development from different dimensions.

From 1978 to 2018, the average level of rural transformation development in the Yangtze River Economic Belt fluctuated between 0.203 and 0.365; the standard deviation was within the range of $0.238-0.387$, indicating that the level of rural transformation development in the Yangtze River Economic Belt was significantly dispersed from the mean, and the degree of non-equilibrium in rural transformation development was relatively high

The standard skewness coefficient of the rural transformation development level in the Yangtze River Economic Belt was within the range of 0.102-0.214; it indicated that the proportion of city units with a lower level of rural transformation development was slightly larger. 
The standard kurtosis coefficient of the rural transformation development level in the Yangtze River Economic Belt changed within the range of 0.022-0.051; it showed that the frequency distribution was smoother than the normal distribution. Based on the statistical analysis of the frequency distribution index, it can preliminarily be concluded that rural transformation and development of the Yangtze River Economic Belt showed a weak distribution since 1978, but this analysis lacked a geographical spatial perspective.

The level of population development transformation in the Yangtze River Economic Belt fluctuated within the range of 0.068-0.118; the level of land use transformation changed within the range of 0.084-0146, and the level of industrial development transformation evolved within the range of 0.051-0.099 from 1978 to 2018. During the whole research period, the characteristics of rural transformation development in different dimensions showed "land use transformation level > population development transformation level $>$ industrial development transformation level". This indicates that there were some differences in the various dimensions of regional rural transformation development; how to coordinate the coupling development of rural elements of "population, land use and industry" is an important way to promote rural transformation development in the Yangtze River Economic Belt.

\subsection{Spatial Pattern Differentiation}

The Global Moran's I index was used to analyze the spatial pattern characteristics of the rural transformation development in the Yangtze River Economic Belt [44]. Based on GeaDA095 software, the paper calculated the Global Moran's I value of the rural transformation development level in the Yangtze River Economic Belt from 1978 to 2018 (Table 2); on the test level of $0.1 \%$, the Global Moran's I of rural transformation development level in the Yangtze River Economic Belt was positive, and the value was within the range of 0.3453-0.4892; it indicates that the rural transformation development level of the Yangtze River Economic Belt showed a positive autocorrelation since 1978; the rural transformation development of the Yangtze River Economic Belt presented the spatial evolution trend of "club convergence". At the same time, the Global Moran's I value of the rural transformation development level of the Yangtze River Economic Belt was dominated by the rising trend; the Global Moran's I value increased by $41.67 \%$; it indicates that the positive correlation between the rural transformation development level of the Yangtze River Economic Belt has become increasingly significant, and the spatial agglomeration of rural transformation development has become more and more intense since the reform and opening up.

Table 2. Global Moran's I value of rural transformation development.

\begin{tabular}{ccccc}
\hline Time & Global Moran's & E(I) & Z(I) & P(I) \\
\hline 1978 & I & & 2.45 & 0.001 \\
1988 & 0.3453 & -0.1105 & 2.48 & 0.001 \\
1998 & 0.3936 & -0.1106 & 2.52 & 0.001 \\
2008 & 0.4378 & -0.1105 & 2.59 & 0.001 \\
2018 & 0.4509 & -0.1104 & 2.63 & 0.001 \\
\hline
\end{tabular}

Note: $\mathrm{E}(\mathrm{I})$ is the expected value; $\mathrm{Z}(\mathrm{I})$ is the test value; $\mathrm{P}(\mathrm{I})$ is the significant level.

According to the LISA theoretical formula, the LISA index value of the rural transformation development level was calculated, and the LISA spatial agglomeration map of rural transformation development in The Yangtze River Economic Belt from 1978 to 2018 was drawn (Figure 4). The LISA aggregation graph was divided into four types: (1) H (High)-H (High): the rural transformation development level of the city itself and neighboring cities are both high; (2) H (High)-L (Low): the level of rural transformation development in the city itself is high, and the neighboring city is low; (3) L (Low)-H (High): the level of rural transformation development in the city itself is low, and the neighboring city is high; (4) L (Low)-L (Low): the level of rural transformation development in the city itself and neighboring city are low. 

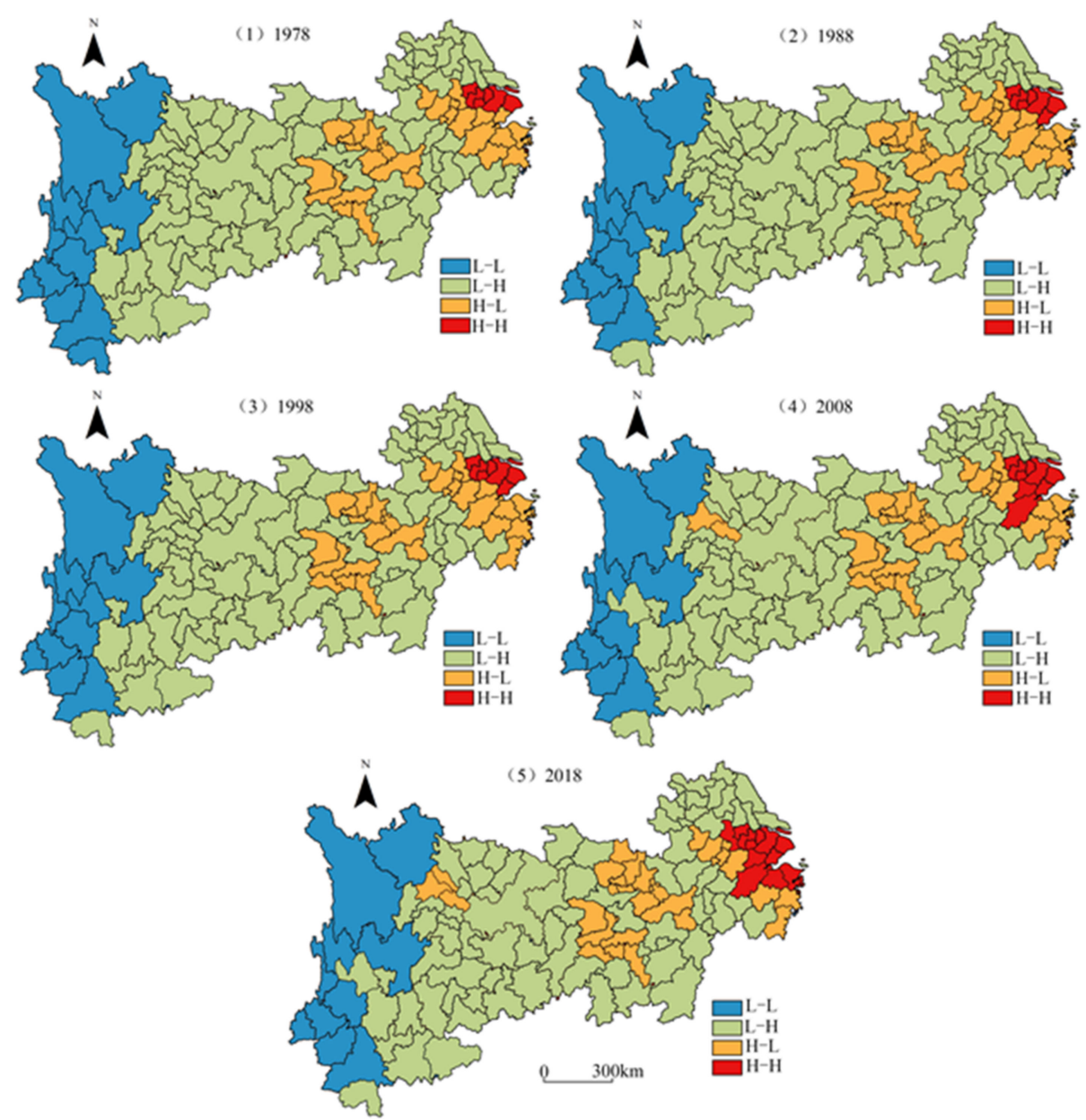

Figure 4. The LISA evolution of rural transformation development in the Yangtze River Economic Belt.

(1) $\mathrm{H}-\mathrm{H}$ type. During the research period, this type was mainly concentrated in the Shanghai and the southern part of Jiangsu, forming a high-value hot spot for rural transformation development in the Yangtze River Economic Belt. After 2008, the Hangzhou-Shaoxing-Ningbo and Wanjiang city belt were evolved into the $\mathrm{H}-\mathrm{H}$ type.

(2) H-L type. This type of spatial differentiation pattern was relatively stable, mainly concentrated in the middle area of the Yangtze River; the Wuhan metropolitan area, Changsha-Zhuzhou-Xiangtan urban agglomeration, southwest Zhejiang urban agglomeration and Chengdu-Chongqing urban agglomeration were the sub-hot spot areas of rural transformation development in the Yangtze River Economic Belt.

(3) L-H type. During the study period, the number of cities in the Yangtze River Economic Belt were the largest, and it was also relatively widespread. It was mainly concentrated in the northern Jiangsu region, southern Anhui region, central Guizhou economic circle and central Yunnan urban agglomeration; only a few cities such as Lijiang, Suizhou and Ziyang were replaced.

(4) L-L type. This type was mainly distributed in the upper reaches of the Yangtze River, such as western Sichuan and the southwest Yunnan region. These areas had poor natural conditions and a poor geographical location; the level of rural development was at a low level, and the capacity for transformation development was low. It was a low-value spatial subsidence area in the rural transformation development of the Yangtze River Economic Belt. 


\subsection{Driving Mechanism}

\subsubsection{Analysis of Influencing Factors}

Theoretically, rural transformation development was mainly influenced by the coupling effects of multiple factors, such as resource endowment, traffic location, economic development and the policy system and so on $[45,46]$. In view of this, the paper selected per capita cultivated land area $\left(\mathrm{X}_{1}\right)$, elevation $<500 \mathrm{~m}$ proportion $\left(\mathrm{X}_{2}\right)$, network density $\left(\mathrm{X}_{3}\right)$, per capita GDP $\left(\mathrm{X}_{4}\right)$, per capita fixed asset investment $\left(\mathrm{X}_{5}\right)$, per capita total retail sales of social consumer goods $\left(X_{6}\right)$ and proportion of agricultural expenditure $\left(X_{7}\right)$ as the impact factors, and the geographic detector model was used to explore the seven specific indicators influencing the rural transformation development of the Yangtze River Economic Belt from 1978 to 2018, to reveal the effect intensity and difference of each indicator factor on the rural transformation development of the Yangtze River Economic Belt in different periods.

Secondly, based on ArcGIS10.2 software, the natural classification of the factors influencing the spatial-temporal differentiation of rural transformation development in the Yangtze River Economic Belt was conducted, and the intensity value $q$ of each indicator factor was measured using Geo Detector software (Table 3). Theoretically, the larger the $q$ value is, the more significant the effect of this factor on the differentiation of rural transformation development will be; it indicates that this factor is the main factor affecting the spatial-temporal differentiation of rural transformation development in the Yangtze River Economic Belt from 1978 to 2018.

Table 3. The influencing factors of rural transformation development.

\begin{tabular}{cccccccc}
\hline Year & $\mathbf{X}_{\mathbf{1}}$ & $\mathbf{X}_{\mathbf{2}}$ & $\mathbf{X}_{\mathbf{3}}$ & $\mathbf{X}_{\mathbf{4}}$ & $\mathbf{X}_{\mathbf{5}}$ & $\mathbf{X}_{\mathbf{6}}$ & $\mathbf{X}_{\mathbf{7}}$ \\
\hline 1978 & 0.32 & 0.25 & 0.41 & 0.51 & 0.45 & 0.39 & 0.35 \\
1988 & 0.27 & 0.21 & 0.42 & 0.56 & 0.49 & 0.42 & 0.38 \\
1998 & 0.22 & 0.17 & 0.44 & 0.60 & 0.55 & 0.45 & 0.41 \\
2008 & 0.17 & 0.14 & 0.49 & 0.65 & 0.59 & 0.48 & 0.44 \\
2018 & 0.12 & 0.09 & 0.51 & 0.69 & 0.62 & 0.52 & 0.45 \\
\hline
\end{tabular}

The effect intensity of indicator factors influencing the differentiation of rural transformation development changed significantly in the Yangtze River Economic Belt in different periods. In general, the action intensity of indicator factors such as per capita cultivated land area $\left(\mathrm{X}_{1}\right)$ and elevation $<500 \mathrm{~m}$ proportion $\left(\mathrm{X}_{2}\right)$ gradually decreased during the study period; it indicates that the influence of natural conditions factors on rural transformation development was weakened. The action intensity of indicator factors such as per capita GDP $\left(\mathrm{X}_{4}\right)$, per capita fixed asset investment $\left(\mathrm{X}_{5}\right)$ and per capita total retail sales of consumer goods $\left(\mathrm{X}_{6}\right)$ was increasing, which were the most important factors affecting spatial differentiation of rural transformation development in the Yangtze River Economic Belt. Furthermore, index factors such as network density $\left(\mathrm{X}_{3}\right)$ and the proportion of agricultural expenditure $\left(X_{7}\right)$ also have significant influences on the rural transformation development differentiation.

\subsubsection{Analysis of the Influence Mechanism}

(1) Natural condition. The difference of natural factors will directly affect the rural resource endowment and land use mode, which is an important basis for the formation of the differentiation pattern of rural transformation development. However, with rapid urbanization and industrialization, the impact of the agricultural economy on rural transformation development is gradually decreasing [47]. The per capita cultivated land area in the upper, middle and lower reaches of the Yangtze River Economic Belt were taken as independent variables; the level of rural transformation development in the corresponding period was the dependent variable for the correlation analysis (Table 4). There was a positive correlation between per capita cultivated land area and rural transformation development, but this positive correlation trend ap- 
peared to be weakening. The upper reaches of the Yangtze River Economic Belt have a superior physical geographical environment; the cultivated land resource is rich, and the rural resource endowment condition is good; it plays a certain role in promoting rural transformation development. The terrain in the lower reaches of the Yangtze River Economic Belt is relatively complex, and arable land resources are scarce. This difference in natural conditions is the basic factor affecting the differentiation of rural transformation development in the Yangtze River Economic Belt.

Table 4. Correlation between rural transformation development level and per capita cultivated land area in the Yangtze River Economic Belt.

\begin{tabular}{cccccc}
\hline $\mathbf{R}$ & $\mathbf{1 9 7 8}$ & $\mathbf{1 9 8 8}$ & $\mathbf{1 9 9 8}$ & $\mathbf{2 0 0 8}$ & $\mathbf{2 0 1 8}$ \\
\hline R (upper reaches) & $0.513^{* * *}$ & $0.468^{* * *}$ & $0.485^{* * *}$ & $0.355^{* *}$ & $0.321^{* *}$ \\
R (middle reaches) & $0.536^{* * *}$ & $0.501^{* * *}$ & $0.472^{* * *}$ & $0.401^{* * *}$ & $0.352^{* *}$ \\
R (lower reaches) & $0.605^{* * *}$ & $0.553^{* * *}$ & $0.463^{* * *}$ & $0.388^{* *}$ & $0.303^{* *}$ \\
\hline Notes: R is the pearson correlation coefficient, significant at the *** 0.01 level ** 0.05 level.
\end{tabular}

(2) Economic social development. Economic and social development factors play a leading role in rural transformation development. With the development of a regional economy and society, especially the acceleration of urbanization and industrialization, and the acceleration of urban and rural population mobility, urban capital and technology and information flow to rural areas, it leads to the constant optimization and adjustment of industrial structures in rural areas and the constant change of landscape, production and lifestyle in rural areas [48]. At the same time, rural transformation development will also have a positive effect on regional per capita GDP, and there is a mutually promoting relationship between them. The rural transformation and development levels of the top eight and the bottom eight cities in the Yangtze River Economic Belt in 2018 were extracted, respectively (Table 5). The average per capita GDP of the top eight cities and the bottom eight cities was 0.422 and 0.170 ; the degree of rural transformation development in cities with a high economic development level was much higher than that in cities with backward economic development. The lower reaches of the Yangtze River Economic Belt have been land of economic and social development, and rural industrialization has laid an important foundation for rural development transformation. In contrast, the process of urbanization and industrialization in the upper and middle reaches is relatively slow; the primitive accumulation of rural development is relatively weak, and the endogenous driving force for rural transformation development is insufficient. This difference in the economic and social development level was the leading factor causing the differentiation of rural transformation development in the Yangtze River Economic Belt.

(3) Traffic accessibility. Traffic accessibility has an important impact on rural transformation development. Rural areas with good traffic conditions are more likely to be influenced by urban radiation, which is conducive to the flow of talent, capital and information so as to better realize rural transformation development [49]. Based on SPSS software, the rural transformation development levels in the upper, middle and lower reaches of the Yangtze River Economic Belt were taken as the dependent variable $\mathrm{Y}$, and the density of traffic network was used as the independent variable $X$ (Figure 5). The rural transformation development in the upper, middle and lower reaches showed a significant positive correlation with the traffic density network, and traffic accessibility was an important condition for rural transformation development. The lower reaches of the Yangtze River Economic Belt are flat; the rural industrialization process is earlier, and the rural transport infrastructure construction level is high; it has a significant promoting effect on the regional rural transformation development. In contrast, the upper reaches of the rural geographical location do not have advantages, and transportation infrastructure is relatively backward. The difference 
of traffic accessibility was the prerequisite factor affecting the rural transformation development in the Yangtze River Economic Belt.

Table 5. Comparison of rural transformation development between the top eight cities and the bottom eight cities in terms of per capita GDP.

\begin{tabular}{cccccc}
\hline City & $\begin{array}{c}\text { Top 8 per } \\
\text { Capita } \\
\text { GDP(Yuan) }\end{array}$ & $\begin{array}{c}\text { Rural } \\
\text { Transformation } \\
\text { Development Level }\end{array}$ & City & $\begin{array}{c}\text { Last 8 per } \\
\text { Capita } \\
\text { GDP(Yuan) }\end{array}$ & $\begin{array}{c}\text { Rural } \\
\text { Transformation } \\
\text { Development Level }\end{array}$ \\
\hline Wuxi & 174,270 & 0.443 & Bozhou & 24,547 & 0.201 \\
Suzhou & 173,765 & 0.457 & Ganzhi & 24,446 & 0.187 \\
Nanjing & 152,886 & 0.432 & Shaoyang & 24,178 & 0.184 \\
Changzhou & 149,275 & 0.378 & Wenshan & 23,568 & 0.164 \\
Wuhan & 145,545 & 0.411 & Xiangxi & 22,885 & 0.172 \\
Hangzhou & 140,180 & 0.422 & Fuyang & 21,589 & 0.158 \\
Changsha & 136,920 & 0.384 & Bazhong & 19,458 & 0.152 \\
Shanghai & 134,982 & 0.455 & Zhaotong & 15,987 & 0.145 \\
\hline Mean & 150,977 & 0.422 & Mean & 22,082 & 0.170 \\
\hline
\end{tabular}
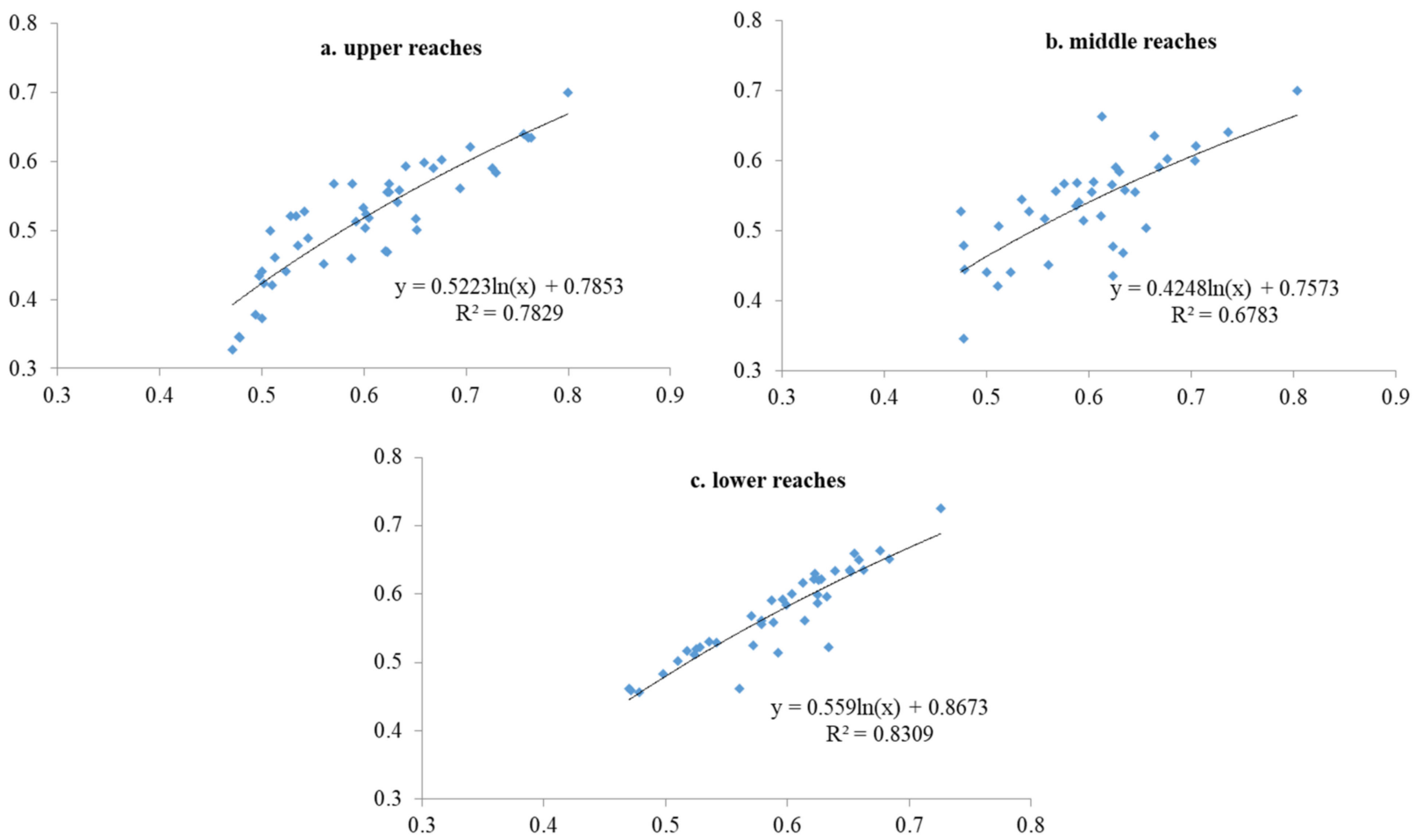

Figure 5. Correlation of rural transformation development and traffic network density.

(4) Policies and systems. The policies and systems directly reflect the government's guidance to regional rural development, and it is an important driving force to promote regional rural development transformation. When policies and systems fail to adapt to the new situation of rural development, it will inevitably lead to difficulty in exerting rural resource advantages and hinder the process of rural transformation development. Integration of urban and rural household registration systems, education policy, social security policy, as well as the adoption of financial discount policy, and so on can effectively guide various factors to flow to rural areas and are an important policy guarantee to realize rural transformation development [50,51]. At present, the lower reaches of the Yangtze River Economic Belt attach importance to rural planning and construction, establish and improve supporting policies for rural transformation development and effectively promote rural transformation development from the 
perspective of macro policy guidance. In contrast, the relevant policies and systems for rural development in the upper and middle reaches were not complete, and the promotion effect of policies and systems on regional rural transformation development was relatively weak. The difference of policies and systems was the driving force of the rural transformation development difference.

On the whole, rural transformation development of the Yangtze River Economic Belt has been mainly influenced by multiple factors, such as natural conditions, economic and social development, traffic accessibility and policies and systems, and the interaction of these factors drove the evolution of the spatial-temporal pattern of rural transformation development in the Yangtze River Economic Belt (Figure 6). In the future, the rural transformation development of the Yangtze River Economic Belt will be spatial-temporal displacement under the influence of these influential factors.

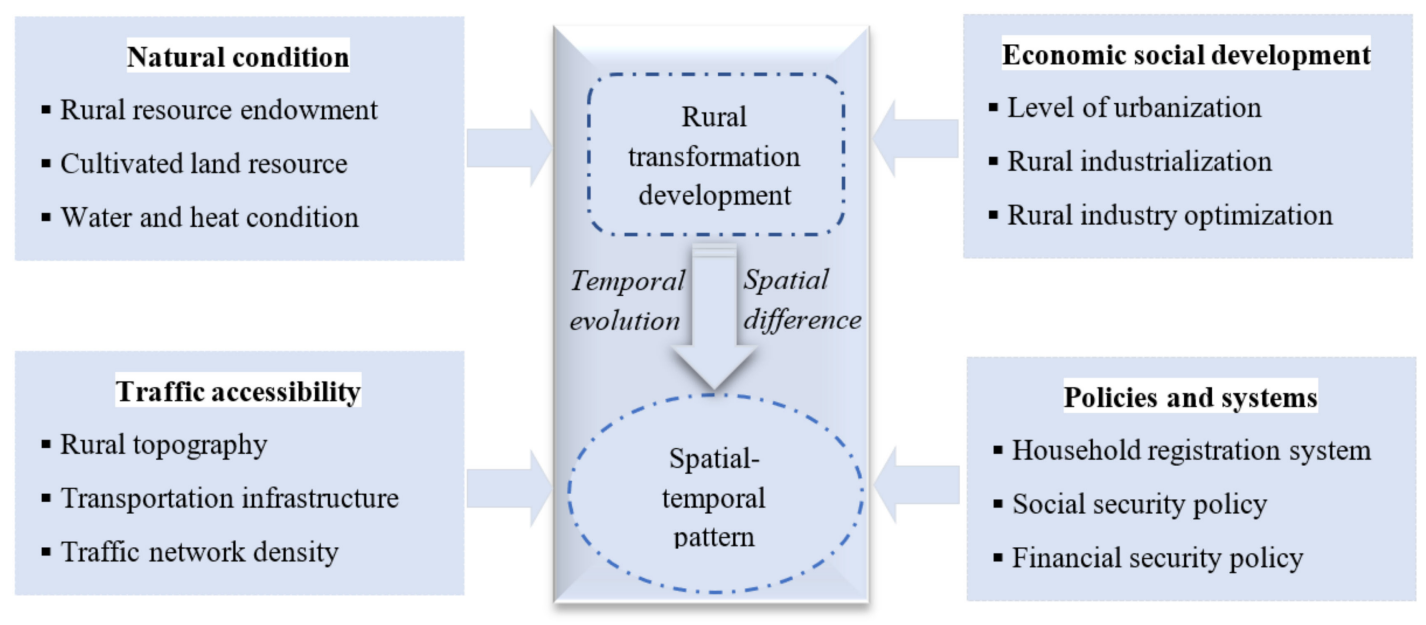

Figure 6. Comprehensive driving mechanisms of rural transformation development.

\section{Discussion}

(1) On the driving mechanism of rural transformation development, Clock [11], based on the regulation theory, proposed to evaluate rural transformation from three dimensions: economic change, social and cultural restructuring and the redesign of the role of the state; this was an important paradigm for explaining the mechanism of rural transformation in developed countries. The market, state and social change mechanisms of rural transformation were more commonly used in Chinese academic circles; most of the literature on the rural transformation mechanism was not opposed to adopting the research framework of the trinity of state, market and society, which could accommodate some new characteristics in the process of rural transformation [52-54]. Through the empirical analysis of the driving mechanism of rural transformation development in the Yangtze River Economic Belt, it could be found that rural transformation development was the result of internal driving forces, foreign aid driving forces and policy driving forces; this empirical conclusion was basically consistent with the views of the above scholars.

(2) According to the spatial agglomeration types of rural transformation development analyzed in the paper, combined with the socio-economic development conditions and leading function positioning of different spatial agglomeration types, different optimization development strategies need to be adopted [55]. (1) The rural transformation development level of the $\mathrm{H}-\mathrm{H}$ and $\mathrm{H}-\mathrm{L}$ types was relatively high; in the future, this type of rural transformation development needs to cultivate a new rural industrial system adapted to the development of urbanization; accelerate the integration of rural first, second and third industries and guide more capital, technology and talent to flow to rural areas. We should develop new rural industries and forms of business 
and promote the in-depth integrated development of agriculture, tourism, cultural industries and other related industries so as to promote the upgrading of traditional rural industries. At the same time, it is necessary to strengthen the rational layout of various elements in rural areas, optimize the "three-life (production, living and ecology)" space in rural areas and improve the regional functions of this type of rural area. (2) The rural transformation development level of the $\mathrm{L}-\mathrm{L}$ and $\mathrm{L}-\mathrm{H}$ types was relatively low; in the future, this type of rural development needs to focus on cultivating talents in rural construction and attracting college students to return home to start businesses. We will train a new type of professional farmer to improve the efficiency of agricultural production activities. We will train a number of rural administrative officials who understand agriculture and love the countryside to modernize rural governance. We should continue to deepen the reform of the rural construction land system, establish a rural collective construction land market system, build a unified urban and rural construction land market, constantly activate the vitality of rural land factors and promote the sustainable transformation and development of this type of countryside. Through classification guidance, it provides practical reference for the rural transformation development in the Yangtze River Economic Belt.

(3) There are still some deficiencies and deepening directions in this paper on the spatialtemporal differentiation of rural transformation development in the Yangtze River Economic Belt under multiple time scales. What are the characteristics of different types of rural transformation development? How can one reveal the role of local government in the process of rural transformation development? In addition, household factors are an important factor affecting rural transformation development; how can one reveal the influencing mechanism of household factors on rural transformation development differentiation in the Yangtze River Economic Belt? This is the direction that this paper needs to deepen further.

\section{Conclusions}

Based on the interpretation of the basic connotation of rural transformation development, the paper constructed an evaluation index system from the perspectives of population transformation, land use transformation and industrial development transformation. Taking the Yangtze River Economic Belt as an empirical region, the paper revealed the spatial-temporal pattern and driving mechanism of rural transformation development. The main research conclusions included the following three aspects:

(1) Through the statistics of the frequency distribution index, it could be seen that the level of rural transformation development in the Yangtze River Economic Belt had a relatively high degree of imbalance since 1978, and urban units with a low level of rural transformation development accounted for a large proportion. In addition, in terms of sub-dimensional characteristics, the sub-dimensional characteristics of rural transformation development showed that land use transformation > population development transformation > industrial development transformation, indicating that there were some differences in various dimensions of rural transformation development in the Yangtze River Economic Belt region, and the rural industrial transformation development level was still at a low level.

(2) Based on the GIS analysis platform, through the analysis of Global Moran's I index, the rural transformation development has manifested the spatial distribution trend of "club convergence" in the Yangtze River Economic Belt. Through the analysis of the Local LISA Index, four different spatial agglomeration types of rural transformation development were obtained; the $\mathrm{H}-\mathrm{H}$ type was mainly concentrated in southern Jiangsu, Shanghai and Hangzhou-Ningbo; the H-L type was mainly concentrated in the Wuhan metropolitan area, Changsha-Zhuzhou-Xiangtan urban agglomeration, southwest Zhejiang urban agglomeration, and Chengdu-Chongqing urban agglomeration; the L-H type was relatively widespread, while the L-L type was mainly concentrated in western Sichuan and southwest Yunnan. The spatial correlation analy- 
sis of rural transformation development is helpful to further clarify the characteristics of the rural transformation pattern in the Yangtze River Economic Belt since the reform and opening up.

(3) Through the empirical study of the geographic detector model, it was concluded that natural conditions, economic social development, traffic accessibility, policies and systems were the leading factors affecting rural transformation development in the Yangtze River Economic Belt. Among them, natural conditions were the basic factors affecting the differentiation of rural transformation development, and the good natural endowment conditions in the lower reaches have laid an important foundation for rural transformation development. Economic and social development was the leading factor affecting the rural transformation; with the continuous improvement of rural industrialization and urbanization, the process of rural transformation development was faster, which was most obvious in southern Jiangsu. Transportation accessibility was a prerequisite factor affecting the differentiation of rural transformation development; rural areas with good transportation conditions were easily influenced by urban radiation, which promoted the flow of factors between urban and rural areas and promoted the transformation. Policies and systems factors were macro factors that affect the differentiation of rural transformation development; policies and systems factors directly reflected the guidance of the government to regional rural development, and they were an important driving force to promote regional rural transformation; the integration of urban and rural household registration systems, education policy and social security policy could effectively guide various factors to flow to rural areas; this was an important policy guarantee to achieve rural transformation development. In the future, the spatial-temporal pattern of rural transformation development in the Yangtze River Economic Belt will continue to evolve due to the comprehensive effect of four factors.

Author Contributions: Conceptualization, R.Z. and X.Z.; methodology, R.Z.; software, R.Z.; validation, R.Z; formal analysis, R.Z.; investigation, R.Z.; resources, R.Z.; data curation, R.Z.; writingoriginal draft preparation, R.Z.; writing - review and editing, R.Z.; visualization, R.Z.; supervision, R.Z.; project administration, R.Z.; funding acquisition, R.Z. All authors have read and agreed to the published version of the manuscript.

Funding: This study was financially supported by the National Natural Science Foundation of China (42101201), by the Humanities and Social Sciences Foundation of the Ministry of Education (20YJCZH230), by Research Project of National Agricultural Professional Degree Graduate Education Steering Committee(2021-NYYB-07) and by the "Qinglan Project" of Yangzhou University.

Institutional Review Board Statement: Not applicable.

Informed Consent Statement: Not applicable.

Data Availability Statement: Not applicable.

Conflicts of Interest: The authors declare no conflict of interest.

\section{References}

1. Woods, M. Rural Geography: Processes, Responses and Experiences in Rural Restructuring; Sage: London, UK, 2005.

2. Liu, Y.S.; Long, H.L.; Chen, Y.F. Progress of research on urban-rural transformation and rural development in China in the past decade and future prospects. J. Geogr. Sci. 2016, 8, 1117-1132. [CrossRef]

3. Mao, D.; Wang, P. The evolution of Western rural restructuring research. Sociol. Res. 2014, 1, 194-245.

4. Diao, X.S.; Eduardo, M.; Jed, S. Cities and rural transformation: A spatial analysis of rural livelihoods in Ghana. World Dev. 2019, 121, 141-157. [CrossRef]

5. Fikri, Z.F.; Ivanie, D.S. Rural transformation, digitalization and subjective wellbeing: A case study from Indonesia. Habitat Int. 2020, 98, 102150.

6. Peou, C. Negotiating rural-urban transformation and life course fluidity: Rural young people and urban sojourn in contemporary Cambodia. J. Rural Stud. 2016, 44, 177-186. [CrossRef]

7. Boris, V. Voices from below: Artisanal and small-scale mining as a product and catalyst of rural transformation. J. Rural Stud. 2016, 47, 108-116. 
8. Hoggart, K.; Paniagua, A. The restructuring of rural spain. J. Rural Stud. 2001, 17, 63-80. [CrossRef]

9. Liu, Y.S. Rural transformation development and new countryside construction in eastern coastal area of China. Acta Geogr. Sin. 2007, 62, 563-570.

10. Long, H.L.; Zhang, Y.N.; Tu, S.S. Rural vitalization in China: A perspective of land consolidation. J. Geogr. Sci. 2019, 29, 517-530. [CrossRef]

11. Cloke, P.; Milbourne, P. Deprivation and lifestyles in rural Wales-II. Rurality and the cultural dimension. J. Rural Stud. 1992, 8, 359-371. [CrossRef]

12. Shubin, S. The changing nature of rurality and rural studies in Russia. J. Rural Stud. 2006, 22, 422-440. [CrossRef]

13. Li, J.T.; Jia, L.R.; Liu, Y.S. Measuring model of rural transformation development path in Fuping County of Beijing-Tianjin-Hebei region. Habitat Int. 2018, 74, 48-56. [CrossRef]

14. Phatharathananunth, S. Rural Transformations and Democracy in Northeast Thailand. J. Contemp. Asia 2016, 46, 504-519. [CrossRef]

15. Li, Y.H.; Li, Y.R.; Westlund, H. Urban-rural transformation in relation to cultivated land conversion in China: Implications for optimizing land use and balanced regional development. Land Use Policy 2015, 47, 218-224. [CrossRef]

16. Ge, D.Z.; Wang, Z.H.; Tu, S.S. Coupling analysis of greenhouse-led farmland transition and rural transformation development in China's traditional farming area: A case of Qingzhou City. Land Use Policy 2019, 86, 113-125. [CrossRef]

17. Klaniecki, K.; Duse, I.A.; Lutz, L.M. Applying the energy cultures framework to understand energy systems in the context of rural sustainability transformation. Energy Policy 2020, 137, 111092. [CrossRef]

18. Suesse, M.; Wolf, N. Rural transformation, inequality, and the origins of microfinance. J. Dev. Econ. 2020, 143, 102429. [CrossRef]

19. Long, H.L. Land use transition and rural transformation development. Prog. Geogr. 2012, 31, 131-138.

20. Li, Z.J.; Ma, X.D.; Sun, S.S. Coupling analysis of rural transformation and land use change in Northern Jiangsu: A case study of Peixian county. J. Jiangsu Norm. Univ. 2015, 33, 36-39.

21. Chen, Y.F.; Su, H.; Liu, Y.S. Reconstruction models of hollowed villages in key agricultural regions of China. Acta Geogr. Sin. 2010, $65,727-735$.

22. Chen, H.W.; Zhang, J.X. Taobao villages: Rural development transformation driven by the space of flow. City Plan. Rev. 2018, 42, 93-101.

23. Saltus, R.; Pithara, C. A sense of dignity in later life: A qualitative study on the views of older women migrants from minoritised backgrounds. Qual. Ageing Older Adults 2014, 15, 21-33. [CrossRef]

24. Wu, X.; Cui, P. A study of the time-space evolution characteristics of urban-rural integration development in a mountainous area based on ESDA-GIS: The case of the Qinling-Daba Mountains in China. Sustainability 2016, 8, 1085. [CrossRef]

25. Imo, E.E.; Olayanju, A.; Ibikunle, F.A.; Dahunsi, S.O. Impact of small hydropower developments on rural transformation in Nigeria. Earth Environ. Sci. 2020, 445, 012023. [CrossRef]

26. Zhou, Y.; Liu, Y.S.; Wu, W.X.; Li, Y. Effects of rural-urban development transformation on energy consumption and $\mathrm{CO}_{2}$ emissions: A regional analysis in China. Renew. Sustain. Energy Rev. 2015, 52, 863-875. [CrossRef]

27. Li, J.T.; Yang, Y.Y.; Jiang, N. County-rural transformation development from viewpoint of "population-land-industry" in Beijing-Tianjin-Hebei region under the background of rapid urbanization. Sustainability 2017, 9, 1637. [CrossRef]

28. Chen, F.; Yu, M.; Zhu, F.W. Rethinking rural transformation caused by comprehensive land consolidation: Insight from program of whole village restructuring in Jiangsu Province, China. Sustainability 2018, 10, 2029. [CrossRef]

29. Cheng, Z.; Cai, J.M.; Cui, L. Facilitating rural transformation development by tourism industry: A case study of Panjin, Liaoning Province. Res. Agric. Mod. 2016, 37, 143-150.

30. Zheng, Z.Y.; Liao, H.P.; Yang, W.; Zhao, Z.Y. On type division and pattern characteristics of the rural areas in Chongqing. J. Southwest Univ. 2018, 40, 104-1112.

31. Tu, S.S.; Long, H.L. Rural restructuring in China: Theory, approaches and research prospect. J. Geogr. Sci. 2017, 27, 1169-1184. [CrossRef]

32. Wang, L.; Khan, Q.U.; Zhang, D. Rural transformation index: Measuring rural-urban disparities. In Skills Development for Inclusive and Sustainable Growth in Developing Asia-Pacific; Springer: Dordrecht, The Netherlands, 2013; pp. 213-240.

33. Onyeonoru, I.P. Labor migration and rural transformation in nigeria. Int. Sociol. J. Int. Sociol. Assoc. 1994, 9, $217-221$.

34. Rufai, A.M.; Ogunniyi, A.I.; Salman, K.K.; Salawu, M.B.; Omotayo, A.O. Rural transformation and labor market outcomes among rural youths in Nigeria. Sustainability 2021, 13, 13794. [CrossRef]

35. Xu, Y.; Peng, Q.Y.; Yin, Y.; Zhong, Q. Evaluating railway operation safety situation in China based on an improved TOPSIS method: A regional perspective. J. Adv. Transp. 2020, 2020, 1796132.

36. Mahmood, T.; Ali, Z. Entropy measure and TOPSIS method based on correlation coefficient using complex q-rung orthopair fuzzy information and its application to multi-attribute decision making. Methodol. Appl. 2020, 10, 1007. [CrossRef]

37. Moura, A.C.; Fonseca, B.M. ESDA (Exploratory Spatial Data Analysis) of vegetation cover in urban areas-Recognition of vulnerabilities for the management of resources in urban green infrastructure. Sustainability 2020, 12, 1933. [CrossRef]

38. Cao, X.S.; Liu, Y.W.; Li, T.; Liao, W. Analysis of spatial pattern evolution and influencing factors of regional land use efficiency in China based on ESDA-GWR. Sci. Rep. 2019, 9, 520. [CrossRef] [PubMed]

39. Robert, H. Spatial Data Analysis: Theory and Practice; Cambridge University Press: Cambridge, UK, 2003. 
40. Wang, J.F.; Haining, R.; Cao, Z.D. Sample surveying to estimate the mean of aheterogeneous surface: Reducing the error variance through zoning. Int. J. Geogr. Inf. Sci. 2010, 24, 523-543. [CrossRef]

41. Wang, J.F.; Xu, C.D. Geodetector: Principle and prospective. Acta Geogr. Sin. 2017, 72, 116-134.

42. Song, Y.Z.; Wang, J.F.; Ge, Y.; Xu, C. An optimal parameters-based geographical detector model enhances geographic characteristics of explanatory variables for spatial heterogeneity analysis: Cases with different types of spatial data. GISci. Remote Sens. 2020, 57, 593-610. [CrossRef]

43. Tae, H.K.; Halbert, W. One more robust estimation of skewness and kurtosis. Financ. Res. Lett. 2004, 3, 56-73.

44. Masot, A.N.; Alonso, G.C. The rural development policy in extremadura (SW Spain): Spatial location analysis of leader projects. ISPRS Int. J. Geo-Inf. 2018, 7, 76. [CrossRef]

45. Klufova, R. Current delimitation and typology of the Czech countryside and its importance for rural development. East. Eur. Countrys. 2016, 22, 229-251. [CrossRef]

46. Murdoch, J. Networks: A new paradigm of rural development. J. Rural Stud. 2000, 16, 407-419. [CrossRef]

47. Openko, I.; Shevchenko, O.; Tykhenko, R.; Tsvyakh, O.; Moroz, Y. Assessment of Inequality to Forest Resources Access in the Context of Sustainable Development. Sci. Pap. Manag. Econ. Eng. Agric. Rural Dev. 2020, 20, 405-410.

48. Collantes, F. Rural Europe reshaped: The economic transformation of upland regions, 1850-2000. Econ. Hist. Rev. 2009, 62, 306-323. [CrossRef]

49. Ahmed, S.; Eklund, E. Rural accessibility, rural development, and natural disasters in Bangladesh. J. Dev. Soc. 2019 , 35, 391-411. [CrossRef]

50. Badri, S.A.; Kazemi, N.; Khodadadi, P. Why rural development policies have not contributed to rural development in Iran. Rural Soc. 2021, 9, 1997423. [CrossRef]

51. Van, B.; Verburg, P.H. Sensitising rural policy: Assessing spatial variation in rural development options for Europe. Land Use Policy 2011, 28, 447-459.

52. Long, H.L.; Li, T.T.; Zou, J. Analysis of dynamical mechanism of rural transformation development in typical regions of China. Econ. Geogr. 2011, 31, 2080-2085.

53. Cao, M.M.; Peng, P.; Wang, X.; Zhou, G.H.; Zhou, R.R.; Liu, X.L. Spatial-temporal evolution characteristics of rural transformation and its influencing factors analysis in Wuling Mountain Area of Hunan Province. Resour. Environ. Yangtze Basin 2020, 29, 1930-1940.

54. Cao, Z.; Li, Y.R.; Chen, Y.F. Approaches to rural transformation and sustainable development in the context of urban-rural integration. Acta Geogr. Sin. 2019, 74, 2560-2571.

55. Belton, B.; Filipski, M. Rural transformation in central Myanmar: By how much, and for whom? J. Rural Stud. 2019, 67, 166-176. [CrossRef] 